\title{
Implementation of the Social Component of Higher Education: Bottom-up Approach
}

\author{
Alla A. Marushkevych \\ Taras Shevchenko National University of Kyiv, Kyiv, Ukraine \\ https://orcid.org/0000-0002-1969-7771 \\ Iryna M. Zvarych \\ Kyiv National University of Trade and Economics, Kyiv, Ukraine \\ https://orcid.org/0000-0003-0715-9551
}

Natalia M. Lavrychenko, Liudmyla Ya. Biriuk and Olha M. Zaitseva

Oleksandr Dovzhenko Hlukhiv National Pedagogical University, Hlukhiv, Ukraine https:/ / orcid.org/0000-0003-0776-7362

https:/ / orcid.org/0000-0003-4940-4228

https://orcid.org/0000-0001-6945-3102

\begin{abstract}
Pedagogical strategies for the implementation of the social content of higher education should be exercised through the application of the bottom-up approach. The bottom-up approach is aimed at ensuring proper development of the student's personality. This approach is based on the subject-specific (academic achievements) and generic (leadership, management skills and focus on personal and professional development) competencies. The purpose of this study was to investigate the range of tools as well as the effectiveness of the bottom-up approach to the implementation of the social component of higher education through perspective development and the emphasis on students' leadership and management skills. The study is of an empirical nature and the research component is based on the formative experimental methodology. Fifteen students of the Faculty of Primary Education participated in the experimental part of the study. They were involved in the specific bottom-up approach to educational environment organization and were evaluated accordingly by a jury. The two-year implementation period of the bottom-up approach to the implementation of the social content of higher education took place through customized projects of personal and professional development. The average socialization readiness level within the group was 78.2 (out of 100 max.), with $13.3 \%$ of students showing an average socialization readiness level, and $86.7 \%$ of students achieving a good level. The results confirmed the effectiveness of the principal notions of the study. The task of adapting the content of higher education in order to achieve a positive momentum of students' socialization readiness was successfully completed. The most promising approach for future
\end{abstract}


research is finding out the advisability and effectiveness of expanding the range of participants of the projects of personal and professional self-development and leadership with the preservation of the essence and identified values of the bottom-up approach.

Keywords: bottom-up approach; higher education institutions; management skills; multisided development; socialization readiness; tertiary education; top-down approach

\section{Introduction}

The ideological and social component of the content of higher education remains a problematic factor (Aleixo et al., 2018) that necessitates scientific and methodological research. In an effort to overcome this problem, researchers often offer comprehensive generalized solutions. In particular, the research involves the paradigm of two opposite approaches which are defined as a bottom-up approach and a top-down approach (very often the classical terms of inductive and deductive approaches are used as synonyms for these).

The agents of progressive social change, according to Fullan (1994), should be tertiary institutions. This is because of the crucially important role of universities in the development of human beings that coincides not only with a period of active professional molding but also personal traits' development. The task of modern humanity is to overcome the separateness and isolation of a person in his/her microcosm or within the scope of petty private interests. Instead, it will require from the individual an understanding of his/her importance as a driver of global social change aimed at the liberation from the chains of the idea of extolling wealth, as well as that of the idea of identifying happiness with material benefits.

In philology the bottom-up approach implies working with each individual lexical unit separately so as to understand the whole text (British Council, 2021). However, in pedagogy it means an attempt to outline the ideological and social essence of modern higher education and involves, analogously, movement from an individual or a separate phenomenon in an effort to outline the integral essence of modern higher education as a mega-important social institution. In a broad sense, the bottom-up approach is an upward (ascendant) movement from the specific to the general. In fact, successful implementation of any reforms in higher education inevitably involves the synergy of both bottom-up and topdown principles (Khelifi, 2019; Singh \& Hardaker, 2017). Understanding of future prospects for promoting higher education and developing models of modernization and innovative approaches to educational paradigms are based more on the generalized syncretic top-down principle (Herodotou et al., 2019). The algorithm of network actions for the practical fulfilment of these ideas can be effectively composed and implemented only through the prism of the bottom-up approach as it is the basis for progressive modern educational management (Khelifi, 2019; Singh \& Hardaker, 2017). 
The specifics of the bottom-up approach implementation depend on the particular aspects of higher education in question: teaching, education, and the integral development of the individual in the paradigm of professional development (Yusof et al., 2018; Warr Pedersen et al., 2017). Thus, bottom-up teaching is predominantly instructor driven and is focused on separate details of teaching the discipline, implying detailing as a way of decoding and simplifying each component through repetition and memorization (Quain, 2018).

Conceptualization of the notion of the bottom-up approach involves outlining the social side of higher education, in particular through the realization of the perspectives of development and leadership in the paradigm of students' personal growth and professional development. In fact, despite the declared three-pronged educational objectives (educatory, disciplinary and evolutive), the process of education in a tertiary educational institution very often turns into digestion of the theoretical foundations of future professional activities. The progressive goal of modern higher education is to identify, reveal, and develop to the fullest extent those qualities of students' personalities that will enable them to fulfil themselves professionally and personally after having graduated from the university. Thus, to socialize in every sense of this concept means to become an active and self-sufficient participant in the social structure.

Therefore the main problem in the context of this study is the need for implementing a bottom-up approach to fill the gap in the fulfilling of the social side of tertiary education.

\section{Literature Review}

\subsection{General Insights of the Problem Articulation}

A literature review on the research topic is severely complicated on the one hand by its generalizing and integrative nature, and on the other hand by the fragmentation, that is a desultory representation of the issue in this form by modern pedagogical science. Starting with the basics - the interpretation of the term 'bottom-up approach', Michell (2016) summarizes this approach as a new age brand of education. In particular, this is justified by the fact that trendy modern pedagogical concepts such as 'self-directed', 'inquiry-based', and 'student agency' are all integrated within bottom-up education as an umbrella term. Mehta et al. (2020) consider the bottom-up approach to be the basis of the strategy for personal development and a part of the deep learning process.

\subsection{Bottom-up Approach within Pedagogical Studies related to Higher Education}

The majority of studies focusing specifically on the bottom-up approach (Galloway \& Numajiri, 2020; Mehta et al., 2020) cover the question of learning a foreign language on the principle of movement from smaller language units (for example, individual lexical items) to the actualization of the meaning of these lexical items in various contexts. The latter require more complex operations of generalization and correlation of the meaning of words in the flow of speech or in the paradigm of the whole text (Moskovsky et al., 2015; Suraprajit, 2019). However, there are currently few studies considering the bottom-up approach 
comprehensively and in an extended sense in terms of the implementation of the social content of higher education. The following are analyzed studies which seem most fully to outline those aspects of higher education relative to the current empirical study.

Kromydas (2017) draws attention to the different ways in which the goals of higher education are achieved and the impact of higher education on society over time. The essence of higher education is close to the apex point of the bottom-up approach, indicating its significance as a social institution. Attention is drawn to the relevance of the discussion in the Western world about the goals of higher education in the context of deepening social inequality in these Western countries. In addition, the consequent interpretation of the model of higher education as a model of mass education relates to both the challenges of higher education and its opportunities (Salmi, 2017). The given context generates an inquiry for solving the issue of the efficiency vs. effectiveness of tertiary education.

There is often concern as to whether higher education should be a priori so democratic and publicly available or whether its primary essence is lost in that case (Fortunato \& Panizza, 2015). For a long time higher education, being the preference of the 'upper crust' was always associated with a certain higher social status; however, nowadays the data regarding the extent of higher education is impressive. Thus, according to Eurostat (2020) reports, in 2019 more than $40 \%$ of the 30-34-year-olds in the EU had completed some tertiary education. Earlier, Marian (2016) also provided even more optimistic data from the 2015 Eurostat sample on the spread of higher education (including associate degrees, higher vocational training and other modern hierarchical forms) in Europe among the population aged 25-64 (average age range of the active productive population). According to them, more than $50 \%$ of 25-64-year-old residents of London, Oxfordshire and neighbouring counties (UK), eastern Scotland, as well as Walloon Brabant (Belgium), Oslo (Norway), Helsinki (Finland), and Zurich (Switzerland) have completed tertiary education. In the situation where every second person of working age has some higher education, it is meaningless to speak of elitism. The prevalence of quantitative indicators of higher education in less developed countries with less established traditions of university education today leads to the problem of irrelevance of the quantitative indicators compared to the quality indicators of higher education (Nadoveza Jelić \& Gardijan Kedžo, 2018; Emrouznejad \& Yang, 2018), which are now being emphasized by the realization of their social content.

Kromydas (2017) compares the modern paradigm of higher education with the ordinary market-place, within which academic achievements and academic degrees are a kind of currency that can be converted into labor market value. Such a shift in the focus of higher education turns the tertiary education into an instrument for economic progress, which also detracts from its primary role of providing the context for full and diverse human development. This actualizes the need for urgent compensation of the worldview-forming and social- 
integrative function, which is traditionally delegated to the institutions of higher education.

Kopycka (2021) writes about the historical and national context of outlining the social side of higher education by exploring the mutual influence of Polish society and tertiary institutions in the diachronic dimension. However, it is safe to say that the values of development and leadership are transcendent for higher education since modernity, and especially today. This can be explained in particular by the growing expansion of the phenomenon of large-scale participation and its penetration into various spheres of social life. Under the conditions of the totalization of mass culture and aggravation of the phenomenon of brainwashing of the population, the roles of critical and selfcritical thinking, readiness to confront destructive tendencies of social life and readiness for active work are increasing steadily (Van Ta \& Zyngier, 2018). All of the above are the basis of a leadership personality.

\subsection{Bottom-up Approach and Personality of a Student}

Brailas et al. (2017) presented the development of an academic course organized according to the principles of complexity theory. The aim of the course is to create a learning organization which is understood by the author as a selforganized whole. Teaching of such a student community is provided based on the strategy of bottom-up knowledge production. In-class face-to-face activities in small groups became the methods of implementing the declared strategy and achieving the set goal. In general, in the bottom-up pedagogical environment, the role of students is to move from full personal development to the model of active partnership (the interim stage between bottom-up and top-down), which is being implemented in the paradigm of a voluntary learning community (Brailas et al., 2017). Bryson (2016) underlines that in such a model the emphasis is on the process and not on the results of educational activities. The primary individuated orientation of the bottom-up approach is the first starting point of this study.

The study is also based on the scientific standpoint of Bergan and Damian (2010). It is the assertion that in the higher education paradigm, students must become proficient in two complex types of competencies, namely subject-specific and generic ones (Bergan \& Damian, 2010). This is the second starting point of present study. In general, in vocational training, mastering of both generalized types of competencies takes place in synthesis provided that full and diverse development of the personality of the student is ensured in a tertiary institution. However, the differentiation into subject-specific and generic competencies is formalized in the structure of any higher education institution with an emphasis on subject-specific competence, while generic competence is not reflected in official educational documents. This will be taken into account in the current research when developing a diagnostic model. A wide range of subject-specific and generic competencies within higher education, according to Bergan and Damian (2010), enables society to solve the most difficult challenges with which it is faced. 
Based on the conducted analysis and in accordance with the observations and practical pedagogical experience of the authors of this study, it can be said that in the context of forming the social side of higher education by bottom-up approach it is necessary to speak about a set of leader and management skills, which, together with subject competencies, enable a student to socialize adequately. The principle for the current study rationale for the bottom-up principle is shown in the following diagram (Figure 1):

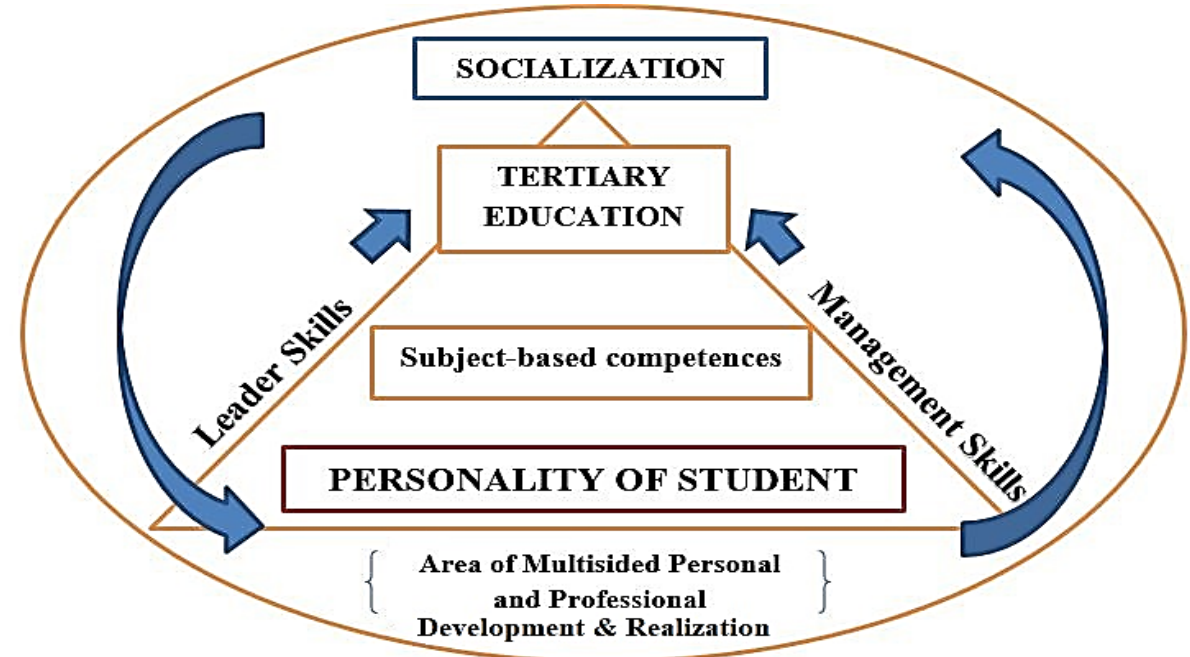

Figure 1: Model of the bottom-up approach to shaping the social side of tertiary education.

Source: Adapted from Bergan and Damian (2010), Brailas et al. (2017) \& Bryson (2016)

The starting point in this case is the student's personality, which in the plane of higher education (triangle), based on the acquisition of subject-based competencies, moves upward to the upper zone of this triangle, which means receiving higher education. However, the sides of this triangle form leader and management skills, without which the structure of higher education itself would not be outlined, therefore, could not exist owing to a lack of integration. Without leader and management skills, the framework of higher education as a construct would be impossible. There is a transition between the upper zone of the triangle and the triangle apex. Socialization is the consequence of obtaining high-quality higher education, the embodiment of the idea of studying at a tertiary institution. Similarly, socialization is unthinkable without tertiary education as its foundation. The arrowed lines show the integration of the process at the general level: the development of the student's personality qualitatively benefits from the process of socialization, while the process of socialization deepens through the development of the student's personality. All this together results in the multifaceted personal and professional development and realization, which depends on the effectiveness of the allelic complementation and integration of vectors of the personality of the student and socialization with the institution of higher education as the driving force and the center of the whole system. The upper and lower planes of the oval can be equated, since socialization is the area of multifaceted personal and professional development and realization. 


\subsection{Principal Standpoints in the Articulation of the Issue of Bottom-up Approach Implementation}

Based on this, the generalized hypothesis of this scientific article comprises the following statements:

i) Pedagogical strategies for the realization of the social content of higher education should be implemented through the application of the bottom-up approach (it is important to note that this does not devalue the top-down approach, which is equally essential for the proper functioning of the educational system);

ii) The very implementation of the social content of higher education is an indicator of its quality, viability and effectiveness as a social institution;

iii) The center of the bottom-up approach is to ensure the proper development of the personality of the student;

iv) The implementation of the bottom-up approach is the key to the socialization of the individual outside the university education system, but in compliance with the paradigm of the values of lifelong learning;

v) The qualities of the student's personality contributing to the implementation of the social content of education are leadership, management skills and orientation towards personal and professional development (the area of generic competencies). However, subject-specific competencies are their basis and context;

vi) It is reasonable to generalize the effectiveness of the implementation of the social content of higher education, which is the subject matter of the present scientific study of the concept of socialization readiness (SR).

\subsection{Aim and Objectives of the Study}

The general purpose of this research is to study the range of tools, as well as the effectiveness of the bottom-up approach to the implementation of the social content of higher education through an emphasis on leadership and management skills of students and orientation towards personal and professional development. The specified purpose involves the implementation of the following tasks:

i) to develop the system of consistent implementation of the bottom-up approach for the best possible socialization of students while studying at the university and after having graduated from it;

ii) to select and substantiate the sample of participants of the empirical experiment;

iii) to conduct an experiment consisting of the emphasized integration of the bottom-up approach to the educational process at the university;

iv) to highlight the success in conducting an experiment; and

v) to draw conclusions about the conducted experiment and to outline prospects for further research.

\section{Method}

The method of a bottom-up approach to implementation is a novel approach, especially in terms of integrating it into the paradigm of tertiary education for enhancing leadership skills and promoting personal development. Thus, the experimental model is fairly innovative and the current research is the first attempt at using it. Nevertheless, it is justified by the principles of higher 
education and the logic of personal development within the context of educational establishments and professional orientation. Theoretically it is supported by the works from the literature review as mentioned below.

The experiment was conducted at Oleksandr Dovzhenko Hlukhiv National Pedagogical University. A total of 15 students of the III (7 people) and IV (8 people) courses of the Faculty of Primary Education participated in the experimental part of the study. The small number of respondents is explained by the nature of the bottom-up approach, which involves upward movement from the student's personality to further generalizations. In this case, a wide range of respondents would be an obstacle to the fully-fledged implementation of the principles of this approach. The very essence of a bottom-up approach would be lost owing to the fact that it would be impossible to pay sufficient pedagogical attention to the development of each student's personality. A specific condition of the sample was that the average academic results were not lower than A or B according to the ECTS-scale for the previous academic year. It is rationalized by the above-mentioned position that subject-specific competencies are the basis and context of the implementation of the social content of higher education through leadership, management and personal and professional development in the field of university education.

During the development of the bottom-up approach model, the view of Bergan and Damian (2010) was regarded as fundamental, namely that the task of universities is not only to train individuals for specific tasks but to educate the person in general. Education is about acquiring skills + values + attitudes.

The inefficiency of the 'big bang' approach is an important feature of the implementation of the bottom-up approach - the fact that it requires time and consistency. The development and implementation of the experiment took two years, while the processing of the final results took another two to three months. Therefore, the experiment was time consuming and required constant correction and attention to the achievements of milestone results. The launch of the experimental program took place in the autumn of 2018.

\subsection{Stages of the Study}

The advantage of the bottom-up approach compared to the opposite top-down approach is that the former approach is student-centered in contrast to the centralized approach to the development and formation of leadership skills of the student as a prerequisite for his/her fully-fledged socialization outside the tertiary institution (initial training educational establishment). In addition to the model of coherent work of the tertiary institution on the implementation of the bottom-up approach which will be presented in the Results section, this requires active and conscientious participation of the student. Therefore, in the first stage, the participants of the experiment were asked to provide answers to the questions on the self-reflective questionnaire (Appendix $\mathrm{A}$, see https://drive.google.com/file/d/1PJlBViuh5g0LbSC1O4AAzchRhL4e6B85/vie $\mathrm{w}$ ? usp=sharing). The analysis of the questionnaires made it possible to develop customized programs for the development of respondents and to outline the anticipated achievements. 
In the second stage, the respondents were required to develop (within two weeks) and to present to the organizers of the experiment independently developed (according to previous instructions from the initiators of the study) projects of personal and professional development and leadership in text format and in the form of a PowerPoint presentation. It was proposed to develop them on the principle of a vision board.

In the third stage, the presented projects of personal and professional development and leadership were approved and step-by-step plans for the implementation of agreed projects were developed. In addition, deadlines were set and reporting forms were prescribed (an example of the project is shown in https://drive.google.com/file/d/1eyVVDfCNeekHhz4luOJ2C3ciNfdIsh23/vie $\mathrm{w}$ ? usp=sharing [See Appendix B]). Individual consultations with studentparticipants of the experiment and organizers took place regularly both by prior arrangement and without notice. Team reporting, discussions of milestone results and exchanges of experiences in the implementation of projects of personal and professional development and leadership took place once a month.

The fourth stage involved the verification of the success of the projects of personal and professional development and leadership by independent members of the jury and with the involvement of the student-participants themselves. The drafting and implementation of projects was done according to a standardized pattern (Table 1), which also made it possible to check the data.

Table 1: Conceptual scheme of development and further evaluation of projects

\begin{tabular}{|c|c|c|c|}
\hline & $\begin{array}{c}\text { Development } \\
\text { vector }\end{array}$ & Methods for implementation & Evaluation \\
\hline 1 & $\begin{array}{l}\text { Subject-specific } \\
\text { competences }\end{array}$ & $\begin{array}{l}\text { The ECTS-scale was used in order to evaluate } \\
\text { student performance. The starting point (bench } \\
\text { mark) for all respondents was } 82 \text { points } \\
\text { (according to the conditions of the sample). } \\
\text { The maximum score is } 100 \text { points. The range of } \\
\text { growth is the difference between the upper } \\
\text { and lower limits, namely } 18 \text { points. Translating } \\
\text { them into a 10-point grading scale } \rightarrow\end{array}$ & $\begin{array}{c}\text { 0-10 points: } \\
\uparrow 1-2 \text { points } \\
=2 \text { scores } \\
3-4 \text { points }= \\
4 \text { scores } \\
\uparrow 5-9 \text { points } \\
=6 \text { scores } \\
\uparrow 10-15 \\
\text { points }=8 \\
\text { scores } \\
\uparrow 16-18=10 \\
\text { scores }\end{array}$ \\
\hline \multicolumn{4}{|c|}{ Generic competences } \\
\hline 2 & $\begin{array}{l}\text { Personal } \\
\text { strategic } \\
\text { thinking skills }\end{array}$ & $\begin{array}{l}\text { Generic competencies include self-planning } \\
\text { skills and the ability of students to identify } \\
\text { aspects of their own development. These were } \\
\text { summarized in the portfolio and during the } \\
\text { survey. }\end{array}$ & 0-10 points \\
\hline 3 & $\begin{array}{l}\text { Effective } \\
\text { communicative } \\
\text { strategies }\end{array}$ & $\begin{array}{l}\text { Effective communicative strategies imply the } \\
\text { ability to communicate effectively and to } \\
\text { organize communication in such a way so as to } \\
\text { achieve pragmatic goals of communication. }\end{array}$ & 0-10 points \\
\hline
\end{tabular}




\begin{tabular}{|c|c|c|c|}
\hline & & $\begin{array}{l}\text { The skills of active listening, empathy, } \\
\text { flexibility; the ability to turn information into } \\
\text { action; the ability to share clear messages and } \\
\text { make complex ideas easy to understand for } \\
\text { others; the ability to inspire and convince } \\
\text { others and foreign language proficiency } \\
\text { (languages skills) were taken into account. } \\
\text { They were evaluated in general terms during } \\
\text { the performance of educational tasks, portfolio } \\
\text { presentation, meetings during the experiment, } \\
\text { and the completion of other research tasks. }\end{array}$ & \\
\hline 4 & $\begin{array}{l}\text { Time } \\
\text { management }\end{array}$ & $\begin{array}{l}\text { This refers to accuracy, the ability to plan } \\
\text { working time efficiently and effectively, to } \\
\text { alternate studying (project work, self- } \\
\text { development and similar) with leisure time, as } \\
\text { well as the timely delivery of all types of work } \\
\text { and performance of specified milestones. }\end{array}$ & 0-10 points \\
\hline 5 & $\begin{array}{l}\text { Decision- } \\
\text { making }\end{array}$ & $\begin{array}{l}\text { Decision-making comprises skills to make } \\
\text { effective and efficient decisions and to look for } \\
\text { the best options for solving problems. These } \\
\text { skills were evaluated in general in the process } \\
\text { of implementing portfolio items. }\end{array}$ & 0-10 points \\
\hline 6 & Team building & $\begin{array}{l}\text { This refers to the ability to work as part of the } \\
\text { team, to organize work in groups so as to } \\
\text { achieve team goals (charity events, initiative } \\
\text { movements, organization of clubs and online } \\
\text { communities of active youth). Each of the } \\
\text { participants had to think about and implement } \\
\text { in their portfolio an item that would include } \\
\text { some of the above-mentioned types of } \\
\text { activities. }\end{array}$ & 0-10 points \\
\hline 7 & $\begin{array}{l}\text { Involvement of } \\
\text { digital resources } \\
\text { to achieve the } \\
\text { goal, namely } \\
\text { advanced ICT } \\
\text { skills }\end{array}$ & $\begin{array}{l}\text { Digital skills are essential to every member of } \\
\text { modern society. The ability of the students to } \\
\text { involve the necessary digital technologies in } \\
\text { solving project tasks, to communicate using } \\
\text { online technologies and to use them for their } \\
\text { self-development was evaluated. }\end{array}$ & 0-10 points \\
\hline 8 & Creative skills & $\begin{array}{l}\text { These refer to the actualization and } \\
\text { development of any type of creativity, hobbies, } \\
\text { sports and similar activities. For every active } \\
\text { member of society, creativity and hobbies are } \\
\text { crucial for the alternation of work and leisure } \\
\text { time and the regeneration of a spiritual } \\
\text { balance. }\end{array}$ & 0-10 points \\
\hline 9 & $\begin{array}{l}\text { Scientific } \\
\text { research }\end{array}$ & $\begin{array}{l}\text { To identify, select and implement a topical area } \\
\text { for research within the specialty or within the } \\
\text { scope of any curriculum subject in the form of } \\
\text { a research study and PowerPoint presentation. }\end{array}$ & $0-10$ points \\
\hline 10 & $\begin{array}{l}\text { Interaction with } \\
\text { potential } \\
\text { employers and } \\
\text { readiness for } \\
\text { future job }\end{array}$ & $\begin{array}{l}\text { Each of the participants in the experiment had } \\
\text { to interact closely with a potential employer or, } \\
\text { ideally, to start working part-time, combining } \\
\text { this with full-time education (according to an } \\
\text { individual schedule). The goal was to start the }\end{array}$ & $0-10$ points \\
\hline
\end{tabular}




\begin{tabular}{|c|l|}
\hline & $\begin{array}{l}\text { practical application of theoretical skills } \\
\text { acquired in the process of studying, deepening } \\
\text { and honing practical skills. Participants could } \\
\text { also undergo training internships and } \\
\text { traineeships included in the curriculum at the } \\
\text { potential place of work. Other possible formats } \\
\text { for the implementation of this item include } \\
\text { working as freelancers in a given specialization } \\
\text { and conducting professional online classes in } \\
\text { the specialization. Participation in } \\
\text { professionally- oriented training and } \\
\text { conferences was also taken into account. }\end{array}$ \\
\hline Socialization readiness level (0-100 scores): \\
$\geq 49$ scores - extremely low \\
$50-65$ scores - sufficient \\
$66-75$ - average \\
$76-85$ - good \\
$86-100$ - excellent
\end{tabular}

Source: Authors' construct

This structure was developed by the authors taking into consideration generalized and interpreted literature review conclusions and authors' collective experience of working within niche of tertiary education. All the students developed their own projects of personal and professional self-development and leadership. Two teacher-mentors were appointed to help each of the respondents. At the drafting stage of the project, teacher-mentors could only consult on the technical side of project design and layout. However, in the process of approval, all five members of the jury panel took part in the discussion. Their task was minor correction of projects, advice on their implementation, and general counselling. Students were told in advance about the necessity to evaluate themselves objectively regarding the possibilities of implementing the plans as outlined in the projects.

The fifth stage was summarizing and outlining the prospects for further research in this field.

\subsection{Methods}

Realization of the goal of research and performance of all tasks required the use of such special scientific methods such as the following:

- design methods (method of academic and educational achievements, method of personal and professional development);

- $\quad$ questionnaire method (using open questionnaires);

- $\quad$ method of conducting an experiment;

- method of concerted action (holding meetings and consultations) and method of organizational and guiding recommendations (providing explanations and instructions);

- $\quad$ methods for empirical data collection and compilation;

- $\quad$ mathematical calculations for interpretation of numerical data (using

Miscrosoft Excel); and

- graphical representation of research results. 


\section{Results}

4.1. The results of Project Implementation of Personal and Professional Development and Leadership of Students

Verification of the results of the implementation of the presented projects was carried out according to the scheme shown in Table 1. In order to individualize the generalization of empirical data, each participant was given an appropriate serial number, which was assigned to him/her for the duration of the experiment. Each member of the jury gave scores to each participant for each criterion in the experimental study. Average indicators were entered into the project table (except for subject-specific competencies, where only objective indicators of academic performance based on the results of end-term tests and examinations were taken into account). The verified data obtained are summarized separately in Table 2 in the context of each individual respondent.

Table 2: Verified results of project implementation of personal and professional development and leadership of students

\begin{tabular}{|c|c|c|c|c|c|c|c|c|c|c|c|}
\hline $\begin{array}{l}\text { No of } \\
\text { respondent }\end{array}$ & $\begin{array}{l}\text { U } \\
\text { W } \\
-\end{array}$ & 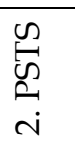 & $\begin{array}{l}\sum_{11}^{n} \\
\text { के }\end{array}$ & $\begin{array}{l}\sum_{\dot{H}} \\
\dot{+}\end{array}$ & $\underset{⿱ 宀 㠯}{\sum}$ & $\stackrel{\infty}{0}$ & $\frac{\stackrel{\tilde{D}}{\Lambda}}{\wedge}$ & $\bigcup_{\infty}^{\infty}$ & $\begin{array}{l}\text { जै } \\
\text { a }\end{array}$ & 穴 & $\begin{array}{c}\text { Total } \\
\text { scores } \\
(0-100)\end{array}$ \\
\hline $\mathbf{1}^{\text {st }}$ resp. & 4 & 8,9 & 9,3 & 7,9 & 8,7 & 7,4 & 8,3 & 8,9 & 9,2 & 7,5 & 80,1 \\
\hline $2^{\text {nd }}$ resp. & 4 & 7,7 & 8,3 & 8,2 & 7,5 & 9,1 & 7,6 & 6,9 & 9,7 & 8,2 & 77,2 \\
\hline $3^{\text {rd }}$ resp. & 6 & 6,9 & 7,4 & 8,8 & 9,4 & 9,7 & 6,9 & 7,3 & 8,9 & 8,4 & 79,7 \\
\hline $4^{\text {th }}$ resp. & 8 & 6,6 & 7,8 & 7,7 & 7,9 & 9,0 & 8,2 & 9,1 & 8,2 & 8,1 & 80,6 \\
\hline $5^{\text {th }}$ resp. & 4 & 7,0 & 8,9 & 8,8 & 7,5 & 6,8 & 9,2 & 9,0 & 7,4 & 7,6 & 76,2 \\
\hline $6^{\text {th }}$ resp. & 4 & 7,4 & 8,8 & 8,6 & 9,2 & 7,4 & 8,3 & 9,2 & 6,0 & 7,3 & 76,2 \\
\hline $7^{\text {th }}$ resp. & 7 & 8,8 & 7,7 & 8,4 & 7,7 & 9,1 & 7,6 & 9,7 & 9,2 & 6,9 & 82,1 \\
\hline $8^{\text {th }}$ resp. & 2 & 9,2 & 6,0 & 8,6 & 8,2 & 7,6 & 8,5 & 6,7 & 9,2 & 7,1 & 73,1 \\
\hline $9^{\text {th }}$ resp. & 4 & 9,7 & 9,2 & 8,5 & 6,7 & 6,6 & 7,8 & 9,3 & 8,7 & 6,3 & 76,8 \\
\hline $1^{\text {th }}$ resp. & 6 & 7,2 & 9,8 & 6,7 & 9,2 & 7,0 & 8,9 & 8,0 & 8,4 & 6,4 & 77,6 \\
\hline 11 $^{\text {th }}$ resp. & 4 & 8,8 & 8,6 & 7,4 & 8,3 & 8,8 & 7,5 & 7,9 & 9,5 & 8,9 & 79,7 \\
\hline $12^{\text {th }}$ resp. & 4 & 8,5 & 8,2 & 9,1 & 7,6 & 8,6 & 9,2 & 8,9 & 7,0 & 7,1 & 78,2 \\
\hline $13^{\text {th }}$ resp. & 6 & 7,0 & 7,7 & 9,1 & 6,7 & 9,2 & 6,4 & 8,8 & 8,6 & 7,3 & 76,8 \\
\hline 14th resp. & 4 & 8,0 & 8,9 & 9,2 & 9,3 & 8,7 & 9,2 & 8,5 & 8,2 & 6,4 & 80,4 \\
\hline $1^{\text {th }}$ resp. & 4 & 6,9 & 9,0 & 6,6 & 8,4 & 9,1 & 7,0 & 8,6 & 9,4 & 6,6 & 75,6 \\
\hline Averagely & 4,7 & 7,9 & 8,4 & 8,2 & 8,2 & 8,37 & 8,1 & 8,5 & 8,5 & 7,3 & 78,2 \\
\hline $\begin{array}{l}\text { Notes: } \\
\text { 1. SSC - Sub } \\
\text { 2. PSTS - Pei } \\
\text { 3. ECS - Effe } \\
\text { 4. TM - Time } \\
\text { 5. DM - Dec } \\
\text { 6. TB - Tean } \\
\text { 7. DR - Invo } \\
\text { 8. CS - Creat } \\
\text { 9. SR - Scien } \\
\text { 10. EI - Inter }\end{array}$ & $\begin{array}{l}\text { ct-sp } \\
\text { onal } \\
\text { ive c } \\
\text { nane } \\
\text { ion-1 } \\
\text { ouild } \\
\text { eme } \\
\text { e sk } \\
\text { ic re } \\
\text { tion }\end{array}$ & $\begin{array}{l}\text { ific c } \\
\text { rateg } \\
\text { nmu } \\
\text { emen } \\
\text { aking } \\
\text { ig } \\
\text { of di } \\
\text { s } \\
\text { arch } \\
\text { ith }\end{array}$ & $\begin{array}{l}\text { mpet } \\
\text { thin } \\
\text { icati }\end{array}$ & $\begin{array}{l}\text { nces } \\
\text { ing sl } \\
\text { strat }\end{array}$ & gies & 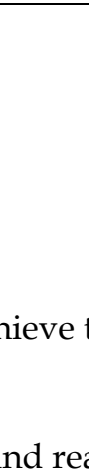 & & 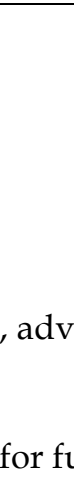 & & & \\
\hline
\end{tabular}

The average indicators within the group of respondents according to the ten criteria components of socialization readiness level are shown in graphic form in Figure 2. 


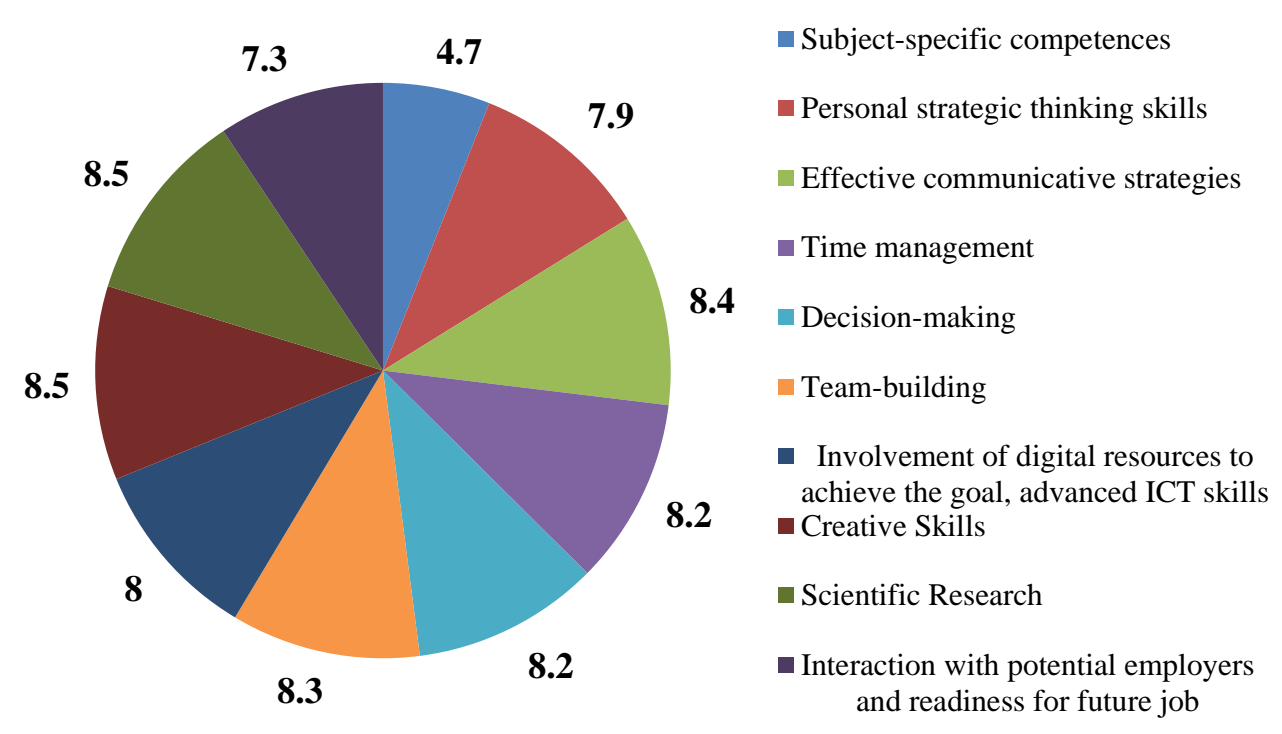

Figure 2: Indicators of the socialization readiness concept (averaged data within the group of respondents)

Next, the obtained average and total indicators for each respondent were interpreted according to the socialization readiness level (Table 3).

Table 3: Socialization readiness level (0-100 scores)

\begin{tabular}{|c|c|c|}
\hline No of respondent & Total scores (0-100) & $\begin{array}{c}\text { Detected socialization readiness } \\
\text { level (0-100 scores) }\end{array}$ \\
\hline $\mathbf{1}^{\text {st }}$ resp. & 80,1 & Good \\
\hline $\mathbf{2}^{\text {nd }}$ resp. & 77,2 & Good \\
\hline 3 $^{\text {rd }}$ resp. & 79,7 & Good \\
\hline $\mathbf{4}^{\text {th }}$ resp. & 80,6 & Good \\
\hline $\mathbf{5}^{\text {th }}$ resp. & 76,2 & Good \\
\hline $\mathbf{6}^{\text {th }}$ resp. & 76,2 & Good \\
\hline $\mathbf{7}^{\text {th }}$ resp. & 82,1 & Good \\
\hline $\mathbf{8}^{\text {th }}$ resp. & 73,1 & Average \\
\hline $\mathbf{9}^{\text {th }}$ resp. & 76,8 & Good \\
\hline $\mathbf{1 0}^{\text {th }}$ resp. & 77,6 & Good \\
\hline $\mathbf{1 1}^{\text {th }}$ resp. & 79,7 & Good \\
\hline $\mathbf{1 2}^{\text {th }}$ resp. & 78,2 & Good \\
\hline $\mathbf{1 3}^{\text {th }}$ resp. & 76,8 & Good \\
\hline $\mathbf{1 4}^{\text {th }}$ resp. & 80,4 & Good \\
\hline $\mathbf{1 5}^{\text {th }}$ resp. & 75,6 & Good \\
\hline Average & $\mathbf{7 8 , 2}$ & \\
\hline
\end{tabular}

Thus, the results of the verification revealed that in the group of respondents for the two-year implementation period of the bottom-up approach to the realization of the social content of higher education, the average indicator of the socialization readiness level within the group was 78.2. According to the assessment system developed and substantiated in the previous section of this study, this is equivalent to a good level of socialization readiness. 
The quantitative distribution of respondents according to the achieved levels is represented in graphic form in Figure 3.

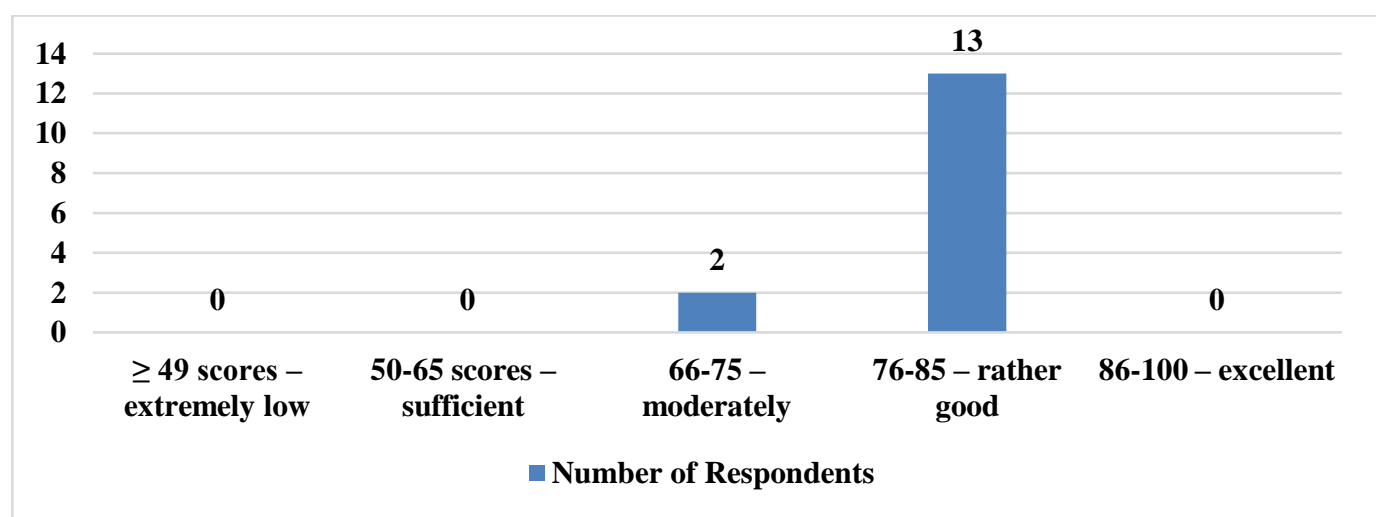

Figure 3: Distribution of respondents according to the achieved socialization readiness level

The results of the experiment can be evaluated positively. This is also substantiated by anonymous estimates of participation in the experiment, which were given by the participants after the final stage of verification (by secret ballot). A total of 13 out of 15 participants $(86.7 \%)$ rated the consequences of participation in the experiment for the development of their own leadership and managerial skills within 8-10 points on the ten-point scale. The absence of respondents in the two left columns of the diagram (Figure 3) can be seen as proof of positive dynamics. At the average level, which can be interpreted as acceptable but not desirable, there are only two participants, which is equivalent to $13 \%$ of all students involved in the study. However, none of the students reached the excellent level, which can be explained by several reasons. In particular, it may be as a result of the level of socialization which is a priori difficult to achieve beyond the actual practice of professional activities in adult life, not limited to the traditions of university education. Lack of socialization practice inevitably affects the socialization readiness level. However, another explanation for this can be found in a rather rigid system of evaluation criteria. Nevertheless, the latter is considered to be well motivated, therefore adaptation of the evaluation system in order to achieve artificially modelled indicators is totally unacceptable.

The whole process of conception, development, implementation and generalization of the experiment makes it possible to identify the following trends in the planning and implementation of a bottom-up approach by tertiary institutions:

- conditional differentiation of subject-based competencies and generic competencies;

- $\quad$ student's personality is the center of the approach;

- implementation of the social component of higher education is organized with an emphasis on leadership and management skills that tend towards the paradigm of generic competencies, but cannot be implemented without the foundation subject-based competencies;

- $\quad$ the need for teamwork of university staff; 
- $\quad$ the need for active involvement of students' extracurricular activities;

- the converse of the aforementioned trend is the extremely low level of shaping the social side of tertiary education, and in particular and within its scope $\rightarrow$ low level of formation of mindset to personal and professional development $\rightarrow$ low socialization readiness level $\rightarrow$ devaluation of higher education values in terms of realization of the social demand for the leader's personality as a key agent of the modern digitalized and mass-oriented society in terms of the collective identity of society; and

- $\quad$ it is time consuming but necessary for both the staff of the tertiary institutions and for the student to put in significant efforts.

For now, it is impossible to increase the number of students who can participate in specialized projects of personal and professional development and leadership. Because of this, only a limited number of students can be involved in such projects. The preference is given to the students with very high levels of academic achievement (which is the basis of generic competences formation).

As for the recommendations for the preliminary adoption of the draft, it could be a good practice to involve the personnel in the paradigm of work of tertiary institutions, especially those trained for the implementation of the socialization readiness concept within the scope of extracurricular activities of the students.

Another recommendation is to introduce the method of personal and professional self-development projects systematically from the first year of studying, but with explicit milestones after every two years of study in a tertiary institution.

\subsection{Limitations and Implications for the Research}

In carrying out the planned experiment, the fundamental principles of the bottom-up approach were taken into account as specifically as possible. These principles were identified in the analysis of relevant scientific literature on the subject. Since it is a person-centered approach, it was impractical to involve large groups of participants in the initial experiment in this field as it would hinder the examination and consideration of individual characteristics of the implementation of the bottom-up approach. Because of this, it is somewhat premature to talk about comprehensive generalizations on the bottom-up approach as a way to perform pedagogical tasks regarding the social content of education.

Also, a fully-fledged implementation of the bottom-up approach requires teamwork from a number of tertiary education specialists (teachers, administration, psychologists, student unions, active youth initiative centers, various student organizations) the obligatory deliberate conscious choice of the student, his/her mindset to the development and leadership, as well as strong levels of motivation, transformed into an activity component and selfadministration skills. This can be implemented through an appropriate effective system of communication among the various participants in the bottom-up educational process. Thus, the bottom-up approach is fairly resourceconsuming, and its implementation has a number of limitations. Without 
acknowledging these, all the efforts of this innovative pedagogical technology can fail.

\section{Discussion}

In the current context, it is necessary to focus scientific attention on the development of generic competencies during higher education (Mehta, 2020; Michell, 2016). The basis of generic competencies, which enable people to socialize after graduation from the tertiary institution, is leadership and management skills, and the general mindset of the individual regarding development and self-improvement. Generic competencies, developed on the basis of subject-based competencies, are the key to the socialization of the student and, accordingly, to the implementation of the social content of higher education. This takes place through the transfer into the social system of key values of the result-oriented building of relationships among various members of society. This also includes the ideal of a modern multifaceted personality, a person who is not only able to socialize in society, but can also adapt to it according to his/her ideals. The student comes into the social environment as a fully-fledged participant according to the logic of upward movement, which also means movement from the specific to the general. That is why it is appropriate to describe this process by means of a complex umbrella term, namely 'a bottomup approach'.

This assertion contradicts the need for a top-down teaching approach (Quain, 2018). Top-down teaching emphasizes instruction through context and relies in part on a student's background and experience to acquire knowledge. The topdown approach is based on a solid foundation of the student's specific subject skills; however, it does not help practicing these skills as opposed to the bottomup teaching approach which focuses on each individual student as a potentially crucial link in the social mechanism. On the other hand, focusing only on the bottom-up approach does not take into account context and generalization. Therefore, the ideal option for the implementation of the social content of higher education is an organic combination of bottom-up and top-down approaches (Quain, 2018). Neither top-down nor bottom-up strategies are appropriate for educational reform. What is required is a more sophisticated blend of the two (Fullan, 1994; Farrell, 2000). This is evidenced by the very mechanism of the organization of the presented experiment in the institutionalized formal framework of university education under the guidance of teachers, administration and other officials. Therefore, the principal position is that no bottom-up nor top-down approach could be a mono approach in the context of tertiary education. However, a bottom-up approach is the most relevant for the stimulation of personal skills development, such as leadership skills.

The peculiarity of the bottom-up approach is the equal distribution of the delegated power of influence and the degree of significance among all participants in the learning process. The pedagogically-oriented categories of development and leadership are correlated in this direction in an interesting way. On the one hand, the very essence of leadership in any case tends towards the semantics of exclusivity and clearly dissonates with the semantics of 
equality. However, the dominant idea of leadership qualities and development in the paradigm of understanding of the problem is not limited to individuals. Instead, leadership plays an expansive role in this context, creating a situation of constructive competitiveness that drives the whole mechanism of the educational process and the structure of student associations, thus implementing the principle of the development of everything.

Despite the significant advances of mankind in science and technology, there are the invariable and even acutely relevant demands for a constructive solution by humanity of two basic issues: humanity's two main conflicts - coexistence with nature and coexistence with each other (Fullan, 1994).

Thus, the purpose of higher education as a social institution is not only a theoretical preparation for employment. Even the readiness to pursue a professional activity, which in itself has a clear social content, is impossible if generic competencies are ignored, as is often the case in Western higher education under the influence of the absolutization of subject-based competencies. It is much easier to develop subject-based competencies through the dominant idea of a top-down approach with an emphasis on collective (therefore, less time-consuming and labour-intensive) forms of organization of educational work (Bergan \& Damian, 2010).

In this study, the bottom-up approach functions as a central vector of higher education coverage of the social content of education. In the studied model of a bottom-up pedagogy, the participatory culture of each individual in the educational process and the principle of realization of the tasks of the institutes of modern higher education occur through a nonlinear synergy of members of the student-teaching community (Gómez-Rey et al., 2018). The social content of education is seen in the education of a fully-fledged, versatile, professionallyoriented personality of the applicant with leadership skills. Leadership skills are conceptualized in the positions that were taken into account during the experiment with the involvement of projects of personal and professional development and leadership of student applicants. These included subjectspecific competencies, personal strategic thinking skills, effective communicative strategies, time management, decision-making, team-building, involvement of digital resources to achieve a goal, advanced ICT skills, creative skills, scientific research, interaction with potential employers and readiness for future jobs. They form the socialization readiness level. Owing to the fact that the proposed model of a bottom-up approach is innovative and experimental, subsequent studies on the application of a bottom-up approach should either be based on the developed model, or a reasonable modification of it, especially taking into account the professional characteristics of the respondents. It is also appropriate to determine further the place of top-down approach in the formation of the social component of higher education, as well as the option of quality interaction of these two approaches. 


\section{Conclusions and Recommendations}

As the conducted empirical research has shown, the bottom-up approach is the best way to implement the social component of higher education.

The concept of the level of socialization readiness in order to measure the implementation of social content by the tertiary institutions was introduced. Having been implemented through the project of personal and professional development and leadership, the bottom-up approach to the realization of the social content of higher education has yielded positive results. A total of 13 out of 15 participants $(86.7 \%)$ rated the consequences of participation in the experiment for the development of their own leadership and management skills within 8-10 points on the ten-point scale. The total absence of respondents at the extremely low and sufficient levels of socialization readiness is the manifestation of positive dynamics. At the average level, which can be interpreted as acceptable but not desirable, there were only two participants at the end of the experiment: this is equivalent to $13.3 \%$ of all students involved in the study.

The practical value of the results of the experiment lies in the possibility of using the developed model as a universal one for the implementation of personalityoriented social content of higher education. Similarly, the data obtained within this study and potentially within other studies of a similar nature can form the basis for theoretical generalizations and filling the gaps in higher education through its focus on subject-based competencies and the consequent neglect of generic competencies.

Further research may concern the perspectives of implementation as outlined in the Limitations section of this study. In particular, it would be worthwhile to investigate further the practicability and effectiveness of expanding the range of participants in projects of personal and professional self-development and leadership with the preservation of the essence and identified values of the bottom-up approach.

\section{References}

Aleixo, A. M., Leal, S., \& Azeiteiro, U. M. (2018). Conceptualization of sustainable higher education institutions, roles, barriers, and challenges for sustainability: An exploratory study in Portugal. Journal of Cleaner Production, 172, 1664-1673. https://doi.org/10.1016/j.jclepro.2016.11.010

Bergan, S., \& Damian, R. (2010). Higher education for modern societies: Competences and values. Council of Europe Publishing. https://rm.coe.int/higher-education-formodern-societies-competences-and-values/168075dddb

Brailas, A., Koskinas, K., \& Alexias, G. (2017). Teaching to emerge: Toward a bottom-up $\begin{array}{llll}\text { pedagogy. Cogent } & \text { Education, } & 4(1), & 1-14 .\end{array}$ https://doi.org/10.1080/2331186X.2017.1377506

British Council. (2021). Bottom up. https:/ / www.teachingenglish.org.uk/article/bottom

Bryson, C. (2016). Engagement through partnership: Students as partners in learning and teaching in higher education. International Journal for Academic Development, 21, 84-86. https://doi.org/10.1080/1360144X.2016.1124966

Emrouznejad, A., \& Yang, G. (2018). A survey and analysis of the first 40 years of scholarly literature in DEA: 1978-2016. Socio-Economic Planning Sciences. Recent 
developments on the use of DEA in the public sector, 61(March), 4-8. https://doi.org/10.1016/j.seps.2017.01.008

Eurostat. (2020). Educational attainment statistics. https://ec.europa.eu/eurostat/statisticsexplained/index.php/Educational_attainment_statistics\#Level_of_educational_ attainment_by_age

Farrell, T. S. C. (2000). English teacher development: Top-down, bottom-up or both? $\begin{array}{llll}\text { Teaching and 21(1), Learning, 27-35. } & \text { 21 }\end{array}$ https://repository.nie.edu.sg/bitstream/10497/343/1/TL-21-1-27.pdf

Fortunato, P., \& Panizza, U. (2015). Democracy, education and the quality of government. Journal of Economic Growth, 20, 333-363. https://doi.org/10.1007/s10887-015-9120-5

Fullan, M. (1994). Coordinating top-down and bottom-up strategies for educational reform. In R. J. Anson, (Ed.), Systemic reform: Perspectives on Personalizing Education (pp. 7-24). OERI, USDE.

Galloway, N., \& Numajiri, T. (2020). Global English language teaching: Bottom-up curriculum implementation. TESOL Quarterly, 54(1), 118-145. https:// doi.org/10.1002/tesq.547

Gómez-Rey, P., Barbera, E., \& Fernández-Navarro, F. (2018). Students' perceptions about online teaching effectiveness: A bottom-up approach for identifying online instructors' roles. Australasian Journal of Educational Technology, 34(1), 116-130. https://doi.org/10.14742/ajet.3437

Herodotou, C., Rienties, B., Verdin, B., \& Boroowa, A. (2019). Predictive learning analytics 'at scale': Guidelines to successful implementation in higher education based on the case of the Open University UK. Journal of Learning Analytics, 6(1), 85-95. https://doi.org/10.18608/jla.2019.61.5

Khelifi, S. (2019). Interplay between politics and institution in higher education reform. European Journal of Educational Research, 8(3), 671-681. https://eric.ed.gov/?id=EJ1222293

Kopycka, K. (2021). Higher education expansion, system transformation, and social inequality. Social origin effects on tertiary education attainment in Poland for birth cohorts 1960 to 1988. High Education, 81, 643-664. https:// doi.org/10.1007/s10734-020-00562-x

Kromydas, T. (2017). Rethinking higher education and its relationship with social inequalities: Past knowledge, present state and future potential. Palgrave Commun, 3, 1. https://doi.org/10.1057/s41599-017-0001-8

Marian, J. (2016). Percentage of population with completed tertiary education by region in Europe. Jakub Marian's Language Learning, Science and Art. https://jakubmarian.com/ percentage-of-population-with-completed-tertiaryeducation-in-europe/

Mehta, Y., Fatehi, S., Kazameini, A., Stachl, C., Cambria, E., \& Eetemadi, S. (2020). Bottom-up and top-down: Predicting personality with psycholinguistic and language model features. In C. Plant (Ed.), 2020 IEEE International Conference on Data $\begin{array}{llll}\text { Mining } & \text { (ICDM) } & \text { (pp. }\end{array}$ https://doi.org/10.1109/ICDM50108.2020.00146

Michell, M. (2016). Top-down vs. bottom-up education. Edmentum blog. https:// blog.edmentum.com/sxswedu-2016-top-down-vs-bottom-education

Moskovsky, C., Jiang, G., Libert, A., \& Fagan, S. (2015). Bottom-up or top-down: English as a foreign language vocabulary instruction for Chinese university students. Tesol Quarterly, 49(2), 256-277. https://doi.org/10.1002/tesq.170 
Nadoveza Jelić, O., \& Gardijan Kedžo, M. (2018). Efficiency vs effectiveness: An analysis of tertiary education across Europe. Public Sector Economics, 42(4), 381-414. https://doi.org/10.3326/pse.42.4.2

Quain, S. (2018). The difference between top-down teaching \& bottom-up teaching. Classroom Synonym. https://classroom.synonym.com/difference-betweentopdown-teaching-bottomup-teaching-12059397.html

Salmi, J. (2017). The tertiary education imperative: Knowledge, skills and values for development. Sens Publishers.

Singh, G., \& Hardaker, G. (2017). Change levers for unifying top-down and bottom-up approaches to the adoption and diffusion of e-learning in higher education. Teaching in Higher Education, 22(6), 736-748. https:/ / eric.ed.gov/?id=EJ1222293

Suraprajit, P. (2019). Bottom-up vs top-down model: The perception of reading strategies among Thai university students. Journal of Language Teaching and Research, 10(3), 454-460. https://doi.org/10.17507/JLTR.1003.07

Van Ta, C., \& Zyngier, S. (2018). Knowledge-sharing barriers in Vietnamese higher education institutions (HEIS). International Journal of Knowledge Management (IJKM), 14(1), 51-70. https:// doi.org/10.4018/IJKM.2018010104

Warr Pedersen, K., Pharo, E., Peterson, C., \& Clark, G. A. (2017). Wheels of change in higher education: A collaborative, multi-stakeholder project as a vehicle for sustainability education. International Journal of Sustainability in Higher Education, 18(2), 171-184. http:// dx.doi.org/10.1108/IJSHE-10-2015-0172

Yusof, N., Hashim, R. A., Valdez, N. P., \& Yaacob, A. (2018). Managing diversity in higher education: A strategic communication approach. Journal of Asian Pacific Communication, 28(1), 41-60. https://doi.org/10.1075/japc.00003.yus 